\title{
A geriatric study of self-recovering diabetes conditions (GH-Method: Math-physical medicine)
}

\section{Introduction}

The author, who is a 73-years-old male with type 2 diabetes (T2D), describes how he reversed his severe metabolic disorder conditions via a stringent lifestyle program which is based on his developed GHMethod: Math-physical medicine.

\section{Method}

The author was diagnosed with T2D approximately 25 years ago in 1995. Fifteen years later, in 2010, his average glucose reached up to $280 \mathrm{mg} / \mathrm{dL}$, where his peak glucose occasionally reached up to $\sim 400 \mathrm{mg} / \mathrm{dL}$, and his $\mathrm{HbA1C}$ was $10 \%$. His diabetic complications included five cardiac episodes, without having a stroke, chronic kidney disease, bladder infection, foot ulcer, diabetic retinopathy, and hyperthyroidism. In 2010, when he was 63 years old, three physicians advised him to begin insulin injections which will eventually lead to dialysis treatment. This was his final wake up call. He then decided to rescue his own life through self-study and research on internal medicine, specifically obesity, diabetes, hypertension, hyperlipidemia, heart attack, and stroke; therefore, he focused on the common root cause, which is metabolism improvement and lifestyle change. ${ }^{1}$

By the end of 2014, he developed a computerized mathematical model to evaluate his daily metabolism status. In 2015-2016, he further created four prediction tools of weight, fasting plasma glucose (FPG), postprandial plasma glucose (PPG), and $\mathrm{HbA} 1 \mathrm{C}$, with a prediction accuracy of $95 \%$ to $99 \%$. He was able to successfully reducehis weight from 198 to 178 pounds, shorten his waistline from 44 to 34 inches, drophis glucose from above $200 \mathrm{mg} / \mathrm{dL}$ to approximately $120 \mathrm{mg} / \mathrm{dL}$ and decrease his $\mathrm{HbA1C}$ from $10 \%$ to $7 \%$. His best accomplishment was discontinuing his three diabetes medications on $12 / 8 / 2015$, which he never took them again.

By 2017, all of his previous diabetic complications have subsided and his medical examination reports have confirmed the same outcomes.

By having his diabetes and its complications under control is an important component; however, by trying to reverse his severe diabetes conditions would be more remarkable. The author is a senior citizen who does not have many years of life left. All of his medical doctors told him that diabetes is a non-reversible and a non-curable disease. He is an obstinate research scientist and engineer who does not listen to others casually or yield to situations easily; therefore, in early 2019, he decided to launch his own research and experiments with the possibility of self-recovery of pancreatic beta cells insulin production. He used seven different cutting angles as entry points to investigate this difficult subject. By the end of 2019, healready published his first medical paper based on his findings for this research project. Thus far, he wrote seven additional medical papers related to this topic. He has finally proven that his pancreatic beta cells are actually repairing itself at a slow rate of $2.3 \%$ per year. It is not much, but at least it is moving in the right direction. As a result, within the last six years, the functions of his insulin production have been repaired and improved by $\sim 14 \%{ }^{2}$

\author{
Volume 5 Issue 4 - 2020
}

\author{
Gerald C Hsu \\ Medical Research Scientist, eclaireMD Foundation, USA
}

Correspondence: Gerald C Hsu, Medical Research Scientist, eclaireMD Foundation, USA, Email g.hu@eclairemd.com

Received: June 21, 2020 | Published: July 06, 2020

Since $1 / 1 / 2012$, he measured his finger glucoses four times a day, once for FPG, and three times for PPG. In addition, from 5/5/2018, he utilized a CGM sensor device to collect $\sim 80$ glucoses per day. In summary, he has already collected $\sim 75,000$ glucose data for his medical research. Therefore, as of early 2020 , he decided to further prove his findings on the pancreatic beta cells self-recovery by conducting one more physical experiment on his own body.

During the early period of 2012-2014, whenever he ate a meal containing "starchy" ingredients, such as wheat, flour, bread, noodle, rice, grains, and potato, his PPG would increase to $\sim 200 \mathrm{mg} / \mathrm{dL}$, with no exceptions. Therefore, for the following 6-years from 2015 to 2020 , he avoided them. The past 5-months in the COVID-19 quarantine period (since 1/19/2020), he decided to conduct a special physical experiment on his body. He started to eat toastand kept all the related records about its behavioral and physical phenomena associated with this particular meal.

\section{Results}

As shown in Figure 1, a photo of toast meals, he had a total of 30 meals with toast along with small quantity of vegetables which have a reasonable amount of carbs/sugar, or with high protein food, such as egg and seafood, with no carbs/sugar. These 30 toast meals have an average finger-pierced PPG of $110.6 \mathrm{mg} / \mathrm{dL}$. His average carbs/ sugar intake amount of 21.4 grams, and his post-meal walking of 4,208 steps.

Figure 2 shows primary characters of PPG, such as its waveform (i.e. curve over three hours), maximum value, minimum value, and average value. The top diagram reveals a "synthesized" PPG waveform from 30 toast meals, whereas the bottom diagram depicts these 30 individual candlesticks. ${ }^{3}$ There are some small deviation existing between the primary values of these two diagrams which resulted from different numerical calculation process. The most important characteristic is the maximum (i.e. highest) PPG values which are $136 \mathrm{mg} / \mathrm{dL}$ for synthesized PPG curve and $149 \mathrm{mg} / \mathrm{dL}$ for 30 individual PPG candlesticks. These highest PPG values of 136$149 \mathrm{mg} / \mathrm{dL}$ are much lower than his previous highest PPG record of around $200 \mathrm{mg} / \mathrm{dL}$ resulted from starchy food during 2012-2014.

As shown in Figure 3, a photo of total meals, he had a total of 517 meals with a variety of food ingredients. These 517 total meals have 
an average finger-pierced PPG of $110.8 \mathrm{mg} / \mathrm{dL}$. His average carbs/ sugar intake amount of 13.4 grams, and his post-meal walking of 4,427 steps. These 517 total meals' finger PPG and post-meal walking steps are similar to those 30 toast meals, except for the carbs/sugar amounts which are 13.4 grams for total meals and 21.4 grams for toast meals. Toast meals carbs/sugar amount is $60 \%$ higher than average total meals. If using a linear amplification ratefor his calculation, the toast meals finger PPG should be $110.6 * 1.6=177 \mathrm{mg} / \mathrm{dL}$ which is close to his early PPG of around $200 \mathrm{mg} / \mathrm{dL}$ during 2012-2014. This finding proves that his beta cells have been self-repaired for the past 6 to 8 years.

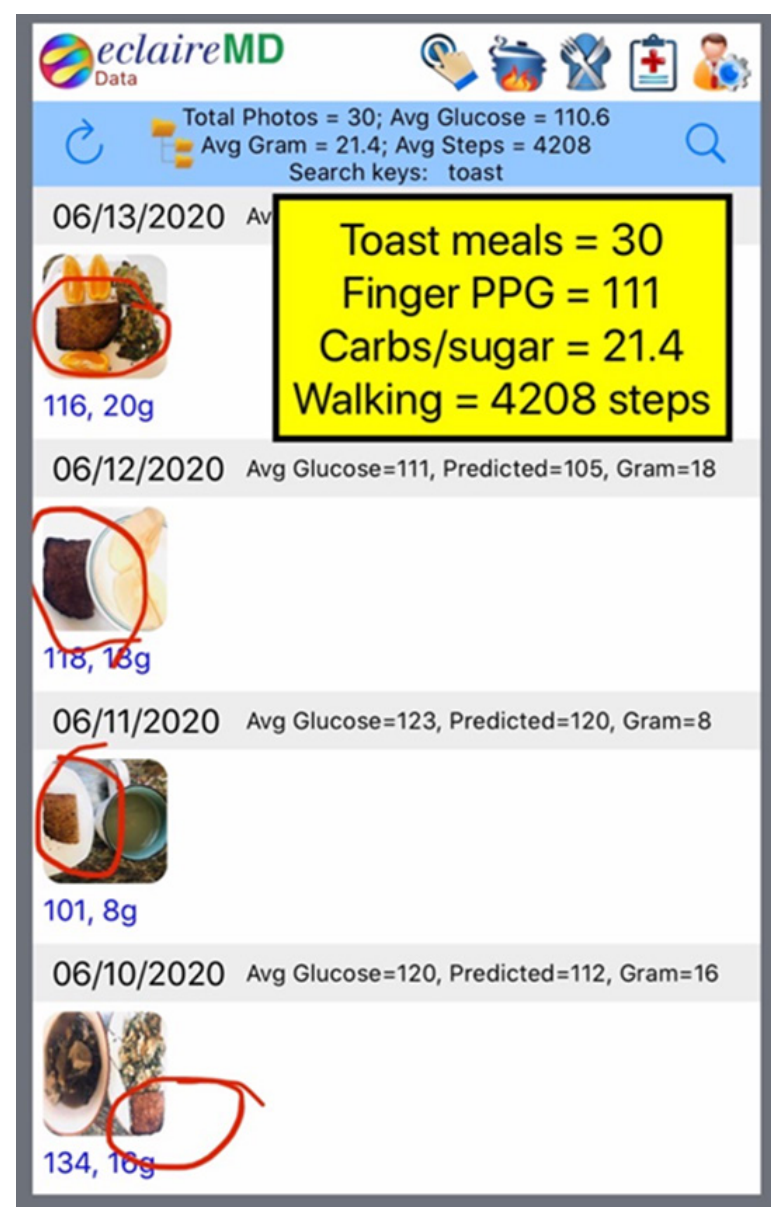

Figure I 30 toast meals (I/I/2020-6/2I/2020).

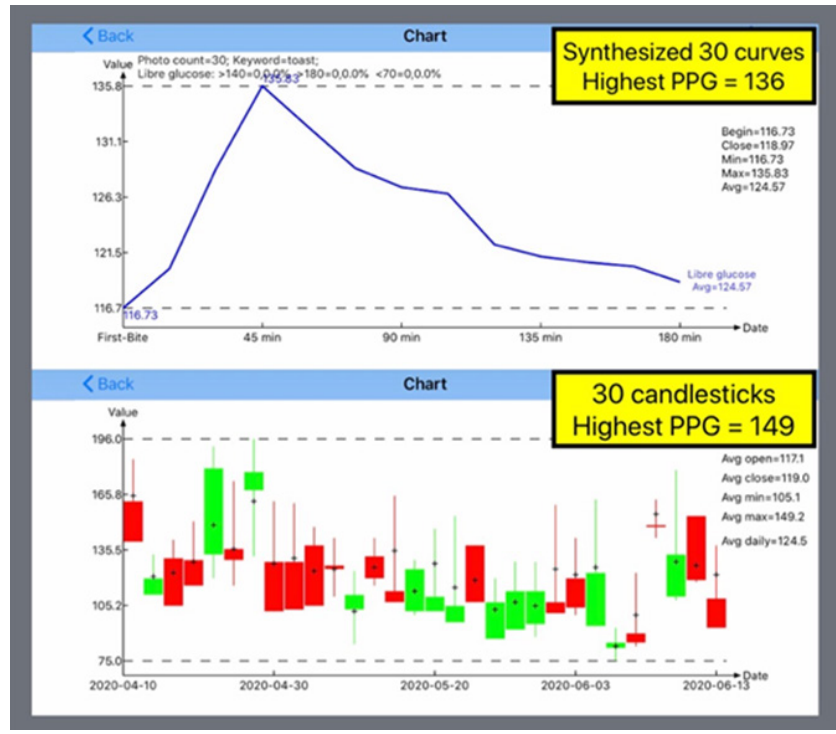

Figure 2 Synthesized PPG curve ad 30 candlesticks chart. 


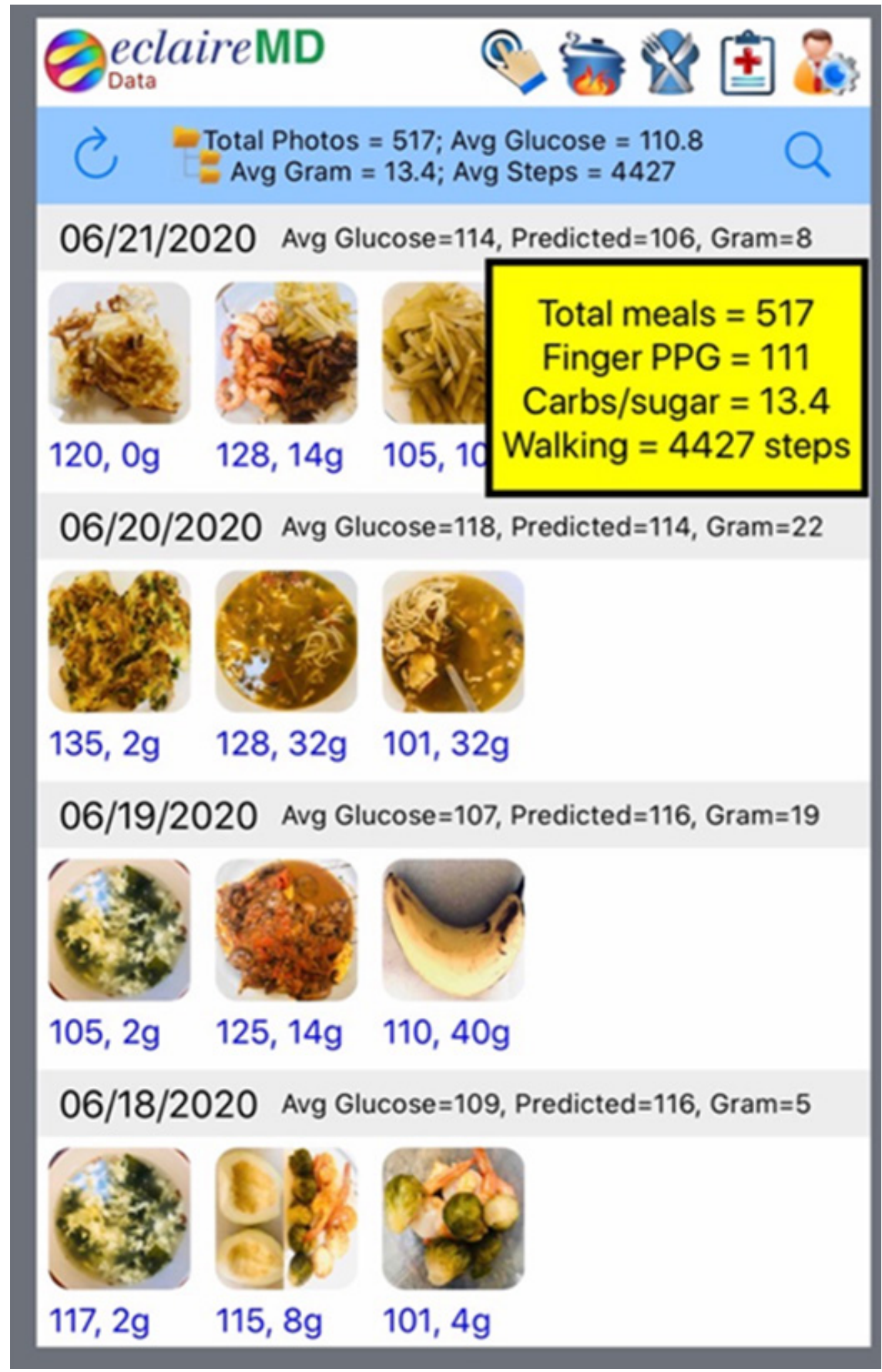

Figure 3517 total meals $(1 / 1 / 2020-6 / 21 / 2020)$.

Figure 4 illustrates a comparison among 30 toast meals, 517 total meals, and 9 decaffeinated coffee. First, in terms of PPG waveform comparison, both toast meals and total meals have remarkably similar waveforms (i.e. curve patterns) with an extremely high correlation coefficient of $91 \%$. This phenomenon means that there are no differences between average toast meals and average total meals. The total meals' peak PPG is $135 \mathrm{mg} / \mathrm{dL}$ while the toast meals' peak PPG is $136 \mathrm{mg} / \mathrm{dL}$. This also means that toast does not have a significant impact on his recent PPG profile in 2020, or his body is starting to treat toast just like any other regular food. Any normal person without diabetes should have this observed "calm" physical phenomenon due to the existence, strength, and capability of a better situation of insulin production. The physical evidence confirms self-recovery of his damaged pancreatic beta cells over the past 6 to 8 years.

Furthermore, he places his recent PPG results from the 9 decaffeinated coffee meals, ${ }^{4}$ which is similar to water intake, along with 30 toast meals and 517 total meals. It is evident that the decaffeinated coffee serves as the "lower bound" of the other meals which havedifferent degrees of carbs/sugar iintake, including toast meals. 


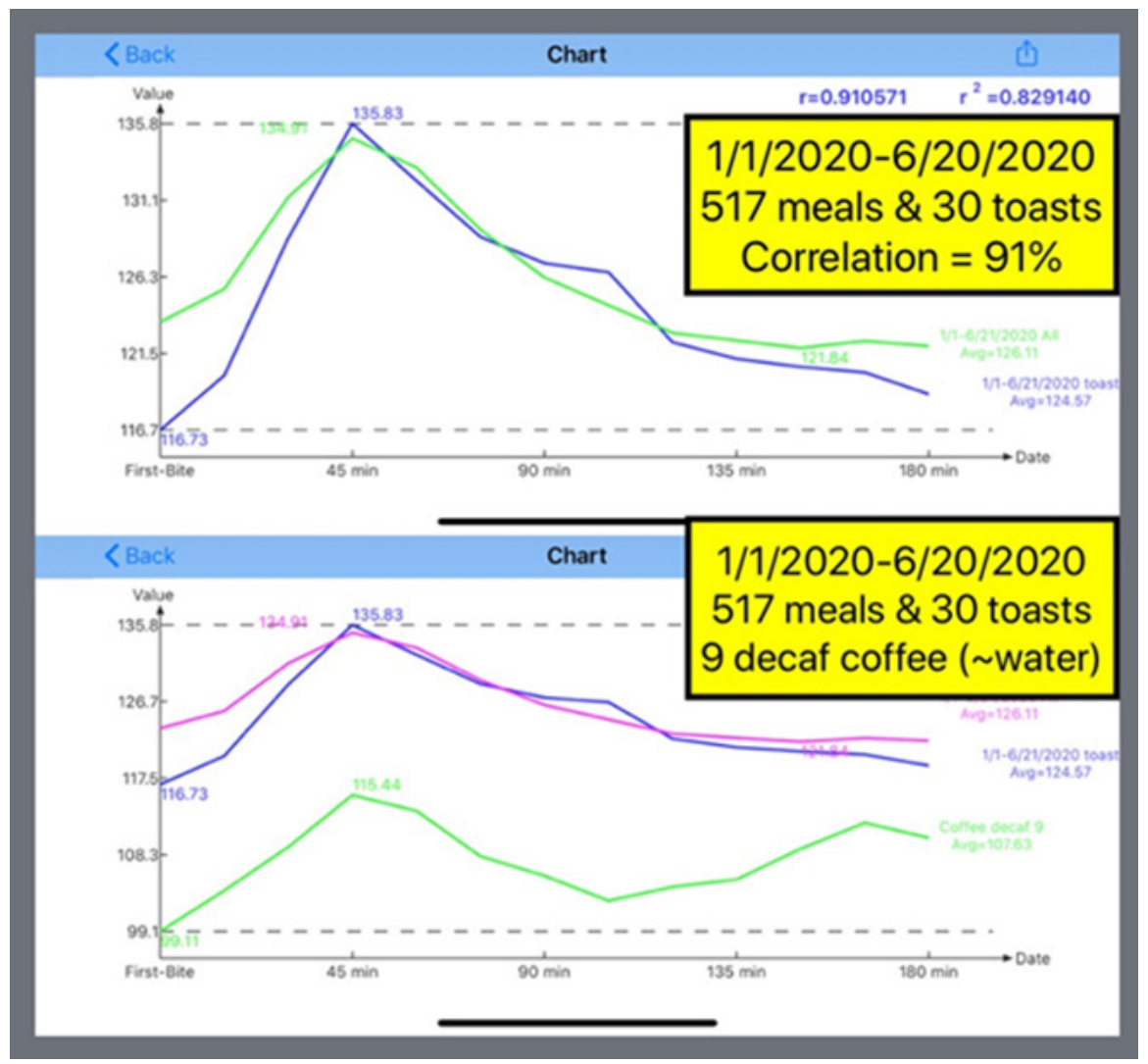

Figure 4 Comparison among toast, total meals, and decaffeinated coffee.

\section{Conclusion}

This simple experiment and its related analysis have provided more physical evidence of reversing the diabetes disease, at least it can be improved through self-repair of the damaged pancreatic beta cells insulin function, even for a 73-year-old, the author himself.

Many senior citizens are suffering from diabetes and dying from its complications. The author's own experiences and research results have proven that seniors, like him, cannot give up. There is hope and available ways to improve our health conditions, which he believes is the underlying fundamental spirit of the geriatric research and practice - to prolong one's life through health improvement.

Life is precious and good health is important. Having a long and healthy life is a dream for everyone. This article provides one logical insight and practical ways to achieve longevity.

\section{Acknowledgments}

First and foremost, the author wishes to express his sincere appreciation to a very important person in his life, Professor Norman Jones at MIT and University of Liverpool. Not only did he give him the opportunity to study for his PhD at MIT, but he also trained him extensively on how to solve difficult problems and conduct any basic scientific research with a big vision, pure heart, and integrity.
The author would also like to thank Professor James Andrews at the University of Iowa. He helped and supported him tremendously when he first came to the United States. He believed in him and prepared him to build his solid engineering and computer science foundation. $\mathrm{He}$ is forever grateful to his mentor, who has a kind heart and guided him during his undergraduate and master's degree work at Iowa.

\section{Conflicts of interest}

The authors declare have no conflict of interest about the publication of this paper.

\section{References}

1. Hsu Gerald C. eclaireMD Foundation. Effective health age resulting from metabolic condition changes and lifestyle maintenance program. USA.

2. Hsu Gerald C. eclaireMD Foundation. A summary report on partial regeneration of the pancreatic beta cells insulin regression using both FPG, PPG, and HbA1C data (GH-Method: math-physical medicine). USA.

3. Hsu Gerald C. eclaireMD Foundation, Comparison study of PPG characteristics from candlestick model using GH-Method: Math-Physical Medicine. USA. 2020:261.

4. Hsu Gerald C. eclaireMD Foundation. Different glucose levels produced by coffee versus decaffeinated coffee (GH-Method: Math-physical medicine). USA. 2020:277. 